\title{
Editorial
}

\section{Guest Editorial: Probabilistic Methods in Fire Safety Engineering}

\author{
Ruben Van Coile, Department of Structural Engineering, Ghent University, \\ Technologiepark-Zwijnaarde 60, 9052 Ghent, Belgium \\ Danny Hopkin, OFR Consultants, Commerce House, Bicester OX264LD \\ Oxfordshire, UK \\ David Lange*, School of Civil Engineering, The University of Queensland, \\ Advanced Engineering Building, Brisbane, QLD 4072, Australia
}

Fire safety engineering is closely linked to the concepts of probability and risk, or as Watts and Hall state in the SFPE Handbook of Fire Protection Engineering: "every decision related to fire safety is a fire risk decision, whether it is treated as such or not" [1]. Although probabilistic and risk-based methods are commonly accepted as tools for the calibration of prescriptive requirements and for performance based design, their application is limited by: (1) a lack of clarity on the position of probabilistic methods in the design process; (2) an absence of applied frameworks which function as a roadmap for probabilistic fire risk assessment; (3) a lack of data to support choices of input (stochastic) variables and probabilistic models; and (4) a limited number of peer-reviewed case studies which can serve as a reference point to the fire engineer.

The purpose of this special issue of Fire Technology is to help diminish the above by presenting to the fire protection community a selection of papers which together constitute both an overview of the state-of-the-art, as well as genuine enhancements to the field of probabilistic fire safety engineering. In total ten articles have been included in the special issue following an open call for papers.

The first paper in this special issue reviews the position of probabilistic methods within fire engineering design. It presents a discussion on what is meant by an $a c$ ceptable level of fire safety, and the relationship between the different risk acceptance concepts applied in probabilistic fire safety engineering. This paper by Van Coile et al. [2] provides background discussion to some of the concepts introduced in the recently published guidance document PD 7974-7:2019 [3].

The following three papers present applied frameworks for probabilistic fire (risk) assessment. On the one hand, Shrivastava et al. [4] and Gernay et al. [5] both present frameworks for probabilistic structural fire safety evaluations. Shrivastava et al. further develop the Performance-Based Earthquake Engineering

\footnotetext{
* Correspondence should be addressed to: David Lange, E-mail: d.lange@uq.edu.au
} 
framework for application to structural fire engineering by focussing on the identification of suitable fire severity measures, whilst Gernay et al. investigate prevailing parameters for defining fire fragility for steel frame buildings. The study by Van Weyenberge et al. [6] on the other hand is concerned with life safety assessments (i.e. available vs. required safe escape time), presenting a quantitative risk assessment framework based on response surface modelling.

The barrier of a lack of data on input probabilities and probabilistic models is addressed by the subsequent four papers. Manes and Rush [7] present a comprehensive list of reference probabilities derived from the 2014 USA fire statistics and compare these to PD 7974-7:2003 recommended values, highlighting large discrepancies between both. As recent historical data is generally not available for postearthquake fires, Farshadmanesh and Mohammadi [8] present an analytical model which supports adjusting normal design situation fire ignition frequencies in consideration of earthquake-induced effects. Li et al. [9] address the lack of fire barrier failure probability data by proposing a model to evaluate this numerically. Xie et al. [10] analyse data from 35 fire load density surveys and provide a probabilistic description for fire load density in offices and residential buildings.

Finally, detailed applications are presented by Heidari et al. [11] and Sabapathy et al. [12]. The case study by Heidari et al. focusses on the probabilistic assessment of simply-supported concrete slabs exposed to parametric fires and has informed the recent ISO/TR 24679-6:2017 [13], while Sabapathy et al. present a comparative safety evaluation for a six-storey commercial building based on expected risk to life.

With the conclusions of the Hackitt report and the recommendation for a move towards the use of safety cases in fire safety engineering [14], it is most likely that interest in the use of probabilistic methods in fire safety engineering will continue to grow. Other initiatives with similar findings around the world have sparked a similar debate (e.g. in Australia the Shergold Weir enquiry [15] highlighted very similar issues and although it stopped short of recommending the safety culture it has contributed largely to debate throughout the fire engineering community as to how to address these issues [16]). The benefit therefore of addressing the listed barriers to the application of probabilistic methods is particularly relevant at this time. This special issue of Fire Technology addresses all four listed barriers to the wider application of probabilistic and risk-based methods in fire safety engineering.

Probabilistic methods provide the fire safety engineer with an additional toolbox for delivering quality projects, and allow the regulator to specify requirements which bring the most net benefit to society. Probabilistic methods provide an opportunity for the fire safety community to perfect communication to stakeholders and fully elucidate the full range of performance which can be reasonably expected from a given design. The guest editors of this special issue believe that the papers published provide a valuable stepping stone towards achieving a wider application of probabilistic methods in fire safety engineering. 


\section{References}

1. Watts JM, Hall JR (2016) Introduction to fire risk analysis. In: Hurley MJ, Gottuk DT, Hall JR, Harada K, Kuligowski ED, Puchovsky M (eds) SFPE handbook of fire protection engineering Springer, New York, pp 2817-2826

2. Van Coile R, Hopkin D, Lange D, Jomaas G, Bisby L (2019) The need for hierarchies of acceptance criteria for probabilistic risk assessments in fire engineering. Fire Technol. https://doi.org/10.1007/s10694-018-0746-7

3. BSI (2019) PD 7974-7:2019. Application of fire safety engineering principles to the design of buildings: probabilistic risk assessment. British Standards Published Document. BSI, London

4. Shrivastava M, Abu AK, Dhakal RP, Moss PJ (2019) Severity measures and stripe analysis for probabilistic structural fire engineering. Fire Technol. https://doi.org/ 10.1007/s10694-018-0799-7

5. Gernay T, Khorasani NE, Garlock M (2019) Fire fragility functions for steel frame buildings: sensitivity analysis and reliability framework. Fire Technol. https://doi.org/ 10.1007/s10694-018-0764-5

6. Van Weyenberge B, Deckers X, Caspeele R, Merci B (2019) Development of an integrated risk assessment method to quantify the life safety risk in buildings in case of fire. Fire Technol. https://doi.org/10.1007/s10694-018-0763-6

7. Manes M, Rush D (2019) A critical evaluation of BS PD 7974-7 structural fire response data based on USA fire statistics. Fire Technol. https://doi.org/10.1007/s10694-018-0775-2

8. Farshadmanesh P, Mohammadi J (2019) A probabilistic methodology for assessing post-earthquake fire ignition vulnerability in residential buildings. Fire Technol. https:// doi.org/10.1007/s10694-018-0811-2

9. Li X, Zhang X, Hadjisophocleous G (2019) A Monte Carlo-based probabilistic barrier failure model for arbitrary fire environment. Fire Technol. https://doi.org/10.1007/s10694-018$0780-5$

10. Xie Q, Xiao J, Gardoni P, Hu K (2019) Probabilistic analysis of building fire severity based on fire load density models. Fire Technol. https://doi.org/10.1007/s10694-0180716-0

11. Heidari M, Robert F, Lange D, Rein G (2019) Probabilistic study of the resistance of a simply-supported reinforced concrete slab according to eurocode parametric fire. Fire Technol. https://doi.org/10.1007/s10694-018-0704-4

12. Sabapathy P, Depetro A, Moinuddin K (2019) Probabilistic risk assessment of life safety for a six-storey commercial building with an open stair interconnecting four storeys: A case study. Fire Technol. https://doi.org/10.1007/s10694-019-00859-z

13. ISO (2017) ISO/TR 24679-6:2017. Fire safety engineering-Performance of structures in fire: Part 6 - Example of an eight-storey office concrete building. International Organization for Standardization Technical Report

14. Hackitt J (2018) Building a safer future-Independent review of building regulations and fire safety: final report, HMSO, ISBN 978-1-5286-0293-8

15. Shergold P, Weir B (2018) Building confidence: improving the effectiveness of compliance and enforcement systems for the building and construction industry across Australia

16. The Warren Centre (2018) Fire Safety Engineering: an enquiry into the issue; The University of Sydney https://static.thewarrencentre.org.au/fire-safety-engineering/

Publisher's Note Springer Nature remains neutral with regard to jurisdictional claims in published maps and institutional affiliations. 